\title{
DAS MUITAS CORES DE UMA CIDADE: O PROJETO ROXO-REI E AS MEMÓRIAS DE NEGROS E DE ÍNDIOS NA PAISAGEM DE OURO PRETO
}

\author{
Nara Rúbia de Carvalho Cunha*
}

\begin{abstract}
Resumo
Este artigo apresenta parte de um projeto desenvolvido, em 2014, entre o Museu Casa Guignard e uma escola da educação básica de Minas Gerais, que enfocou a paisagem da cidade de Ouro Preto numa produção de conhecimentos histórico-educacionais em diálogo com a arte. Em especial, recorta-se a primeira parte desse projeto, na qual foi promovida uma reflexão sobre a presença de índios e de negros na formação dessa paisagem e foi fomentada uma discussão que entrelaçava diferentes temporalidades, promovendo uma comparação entre presente e passado.
\end{abstract}

Palavras-chave: Produção de conhecimentos. Memória. Relações étnico-raciais. Alberto da Veiga Guignard.

\footnotetext{
* Doutora em Educação pela Universidade Estadual de Campinas (Unicamp), onde integra os grupos de pesquisa GEPEC-FE/Unicamp e Kairós-CMU/Unicamp, e professora da Secretaria de Estado de Educação de Minas Gerais. Também é consultora do projeto Roxo-Rei pela Associação de Amigos do Museu Casa Guignard. E-mail: nrcalegria@gmail.com.
} 
1 Para mais informações, acessar a página: $<$ http://www1. cultura.mg.gov.br/>.

\section{Introdução}

Em meados de 2014, teve início uma parceria entre a Associação de Amigos do Museu Casa Guignard (AAMCG) e a Escola Estadual de Ouro Preto (EEOP), ambas localizadas em Ouro Preto, Minas Gerais (MG), visando a realização de um projeto fomentado pelo governo federal através do programa Mais Cultura nas Escolas, desenvolvido pelo Ministério da Cultura (MinC) e pelo Ministério da Educação (MEC).

A AAMCG elaborou, em consonância com as demandas da EEOP, o projeto "Roxo-Rei: interpretação da paisagem pelos passos de Guignard", cujo objetivo geral era contribuir para a formação integral dos estudantes, ampliando os aspectos de compreensão de si mesmos como sujeitos racionais, sensíveis, produtores de culturas - ao mesmo tempo em que são formados por elas - e integrados à paisagem por experiências vividas de forma individual e coletiva. Nesse ínterim, o projeto Roxo-Rei atuava divulgando a obra do artista plástico Alberto da Veiga Guignard, dando destaque à sua interação com a paisagem mineira, principalmente com Ouro Preto, à especificidade de sua arte e à sua atuação como educador. Para atingir tais objetivos, o projeto apostou na produção coletiva de conhecimentos a partir do universo de Guignard, recomposto pela ótica do Museu Casa Guignard (MCG), tanto por objetos integrantes do acervo quanto pelo constante trabalho de pesquisa que tem resultado na produção de material de divulgação e didático-pedagógico, como o mapa-folder Passos de Guignard, a cartilha Paisagem Imaginária e o espaço virtual Projeto Guignard. ${ }^{1}$

Guignard foi um dos mais importantes pintores modernistas brasileiros. Ele nasceu em 1896, em Nova Friburgo, no Rio de Janeiro (RJ), e morou na Europa dos 11 aos 33 anos, quando regressou ao Brasil, onde permaneceu até falecer, em 1962, na cidade de Belo Horizonte, capital de Minas Gerais (MG). Neste estado, o artista viveu seus últimos dezoito anos, hospedando-se em hotéis ou em casas de 
amigos; nesse período, ele demonstrou especial encantamento pela cidade de Ouro Preto, onde pretendia adquirir uma casa própria, mas acabou falecendo antes de concretizar tal sonho. No entanto, ainda em 1960, um grupo de amigos seus idealizou uma fundação destinada a proteger a obra e a memória do artista e, em 1964, foi instituído o Museu Casa Guignard, aberto ao público em 1987 e localizado na Rua Conde de Bobadela, número 110, no centro dessa cidade.

O acervo do MCG reúne desenhos, óleo sobre tela, colagens, objetos pessoais, pinturas feitas em artigos de uso cotidiano (como móveis e instrumentos musicais, entre outros objetos), além do Álbum de Cartões para Amalita Fontenelle, que reúne mais de cem cartões feitos por Guignard, de 1932 a 1937, empregando diversas técnicas e tintas. Na área educativa, em consonância com o perfil educador desse artista e com o acervo de que dispõe, o MCG tem se especializado na realização de oficinas de observação da paisagem, de desenho livre e de confecção de cartões de amor e de amizade, além de desenvolver trabalhos em parceria com professores da educação básica de Ouro Preto, a exemplo da pesquisa-ação Primaveras Compartilhadas, ocorrida em 2012. ${ }^{2}$

Em todos os campos de atuação, o MCG privilegia a interação com o espaço urbano local, tanto o centro histórico quanto os distritos, compreendendo a cidade como "amor inspiração", forma como Guignard se referia a Ouro Preto, sua verdadeira casa. Essa interação com a cidade, transformando-a e sendo por ela transformada, pressupõe, substancialmente, a interação com as pessoas que nela vivem. Por isso, o MCG está em constante diálogo com outras instituições culturais, artistas locais, profissionais ligados à educação e à cultura e com a população de modo geral.

A Escola Estadual de Ouro Preto, por sua vez, desenvolve importante trabalho de inclusão social e de compreensão e respeito às diversidades, apostando na prática de ações coletivas como caminho para a construção da cidadania. A manutenção de uma horta comunitária, a expressão do corpo a partir da roda de capoeira, o estudo da

2 Para mais informações, ver Cunha (2016). 
3 Os alunos que participam do projeto Tempo Integral estão matriculados em turmas do Ensino Fundamental II e permanecem na escola nos turnos da manhã e da tarde, sendo um deles destinado às aulas da grade curricular regular e outro às atividades e projetos especificamente elaborados para o Tempo Integral, sendo priorizados pela escola os projetos culturais que envolvem a comunidade e outras instituições locais. cultura afro-brasileira, os programas de educação ambiental e o projeto Tempo Integral ${ }^{3}$ são alguns exemplos das escolhas políticas e pedagógicas dessa escola, que atende aos segmentos fundamental e médio da educação básica. Além disso, é importante destacar a localização da instituição na Bauxita, bairro mais industrializado e moderno da cidade reconhecida pela Organização das Nações Unidas para a Educação, a Ciência e a Cultura (UNESCO) como Patrimônio Cultural da Humanidade, em setembro de 1980, e que se projeta no cenário nacional e global com uma imagem colonial barroca que, muitas vezes, sobrepõe-se à urbana, sobretudo às características mais modernas ou contemporâneas, fruto de um movimento deliberado desde o início do século XX (ANGOTTI-SALGEIRO, 1996) e promotor de mudanças na percepção da paisagem por seus moradores ou visitantes (OLIVEIRA, 2006).

A escola atende uma comunidade plural, com alunos vindos da Bauxita e de outros bairros adjacentes, como Saramenha e Pocinho, sendo deste a quase totalidade dos alunos do projeto Tempo Integral, que foram diretamente contemplados pelo Roxo-Rei, cujo nome alude a essa região da cidade, visto que, no solo do bairro Pocinho, encontrava-se um ocre utilizado na produção do pigmento de cor roxo-rei. O projeto apropria-se dessa cor como uma alegoria, com vistas a potencializar percepções plurais da cidade e a fomentar, entre os estudantes envolvidos, outros olhares para si mesmos a partir de suas relações com a paisagem, compreendendo-a como construção histórica e cultural e percebendo a presença ativa de cada um deles nessa construção.

A fim de promover os deslocamentos de sentidos e de sensibilidades dos participantes para outros espaços e aspectos da cidade, destacavam-se a arquitetura dos bairros mais modernos e operários, a riqueza mineral do solo e a diversidade de pigmentos naturais que podem ser produzidos a partir dele, e os problemas relacionados à expansão da urbanização, que provoca uma contínua mutação da paisagem. Evitava-se, contudo, limitar o trabalho ao contexto imediato 
da escola e dos estudantes. Nesse sentido, teve destaque, nos encaminhamentos teórico-metodológicos do projeto, uma reflexão baseada no entrecruzamento de temporalidades e na relação entre sujeitos e objetos ou o mundo em que se inserem (SOUZA, 1992), articulando a percepção dos estudantes ao olhar de Guignard sobre Ouro Preto, o qual abarcava desde detalhes do cotidiano a amplos panoramas da paisagem, além de ser constituído por elementos reais e imaginários.

Entre as obras de Guignard envolvidas no projeto e que merecem destaque diante do recorte escolhido para este artigo, está a tela Paisagem Imaginária de Minas, de 1947, integrante do acervo do Museu Casa Guignard, e reproduções de um conjunto de telas que focalizaram o cotidiano de famílias de fuzileiros navais afrodescendentes no Rio de Janeiro, na década de 1930, cujos originais pertencem a colecionadores particulares e a outras instituições. Tais obras permearam discussões ligadas a dois locais da cidade bastante presentes na pintura de Guignard e que compõem o mapa-folder Passos de Guignard: o Morro São João e a Igreja de Santa Efigênia. Como para cada ponto dos Passos de Guignard havia uma programação temática a ser desenvolvida no Roxo-Rei, os temas escolhidos para esses locais foram, respectivamente, "cidade amor inspiração' e a cor ausente" e "cidade amor inspiração': preto, branco e nuances”. Eles foram trabalhados em atividades diversificadas, cada um ao longo de duas semanas. Na programação, estava incluída a reflexão sobre a participação de indígenas e de negros na formação de Ouro Preto e suas presenças/ausências na paisagem contemporânea, o que levava a um questionamento sobre lembranças e esquecimentos que permeiam práticas de memória nos espaços escolar, museológico e urbano.

Para desenvolver o trabalho com ambas as temáticas, foram convidados guias de turismo, estudantes da Universidade Federal de Ouro Preto (UFOP), pesquisadores de iniciação à docência ligados ao Laboratório de Ensino de História (LEHIS/UFOP) e ao Núcleo de Estudos Afro-brasileiros e Indígenas (NEAB/UFOP), além de profissionais do Museu 
Casa Guignard e de professores da Escola Estadual de Ouro Preto. Assim, intencionava-se proporcionar a produção de conhecimentos por meio de um intercâmbio de saberes, linguagens e perspectivas.

\section{Uma paisagem multicolorida}

Para o pleno desenvolvimento da proposta, era fundamental partir de uma compreensão da cultura "como processo, e as identidades coletivas como construções culturais, por isso históricas e relacionais" (ABREU; MATTOS, 2008, p. 41), o que levava à preocupação com a construção historicamente engendrada das "fronteiras" entre os sujeitos, das hierarquizações, dos apagamentos ou da negação do outro e, certamente, das resistências, percebidas também pelo viés da negociação e da ressignificação. Portanto, ao abordar as culturas de afrodescendentes e indígenas, elas não foram tomadas isoladas, mas numa relação contínua com outros grupos étnico-raciais e culturais que constroem suas identidades cotidianamente, reelaborando costumes em meio a tensões e a conflitos (THOMPSON, 1998). Para que os estudantes pudessem compreender melhor essa construção histórica, relacional, tensa e dinâmica, era necessário ir além da superfície da paisagem, por isso, foi incentivada uma escavação de camadas de tempo e de memórias (BENJAMIN, 1995) a partir de lugares e de objetos que marcam a paisagem da cidade.

Assim, a primeira atividade do tema "cidade amor inspiração' e a cor ausente" foi uma visita guiada pelo historiador e guia de turismo André Castanheira Maia ao Morro São João e às ruínas do Morro da Queimada com o intuito de contar a história da cidade, conforme ela geralmente é apresentada, isto é, a partir da chegada dos bandeirantes, enfocando, portanto, a cultura do colonizador. A partir disso, os estudantes foram instigados a pensar sobre as pessoas que viviam na região quando os bandeirantes "chegaram" e sobre os elementos da paisagem que pudessem fazer referência a tais pessoas ou grupos étnico-culturais. 
Dando sequência às atividades, os estudantes da UFOP ligados ao LEHIS ministraram aulas-oficinas sobre a presença-ausência do índio na paisagem de Ouro Preto. Afinal, onde o índio está? Que elementos guardam as memórias de sua presença na paisagem? Além da comparação entre a habitação da região por grupos indígenas em fins do século XVII e na atualidade, seguida de discussão sobre as relações entre colonizadores e os indígenas no Brasil, em Minas Gerais e na região de Ouro Preto, foi promovida uma dinâmica educativa de busca atenciosa aos detalhes da paisagem, partindo da etimologia das palavras que compõem os nomes dos locais, algumas delas de origem indígena e muito marcantes, como o Pico do Itacolomi, marco geográfico da paisagem ouro-pretana. Nos dias seguintes, os professores da EEOP deram sequência às investigações sobre as marcas da presença-ausência dos indígenas na paisagem de Ouro Preto, inclusive em lugares de memória (NORA, 1993) como os museus, questionando: O índio está nos museus da cidade? Se está, como está? Quem narra a presença do índio na formação da paisagem da cidade? Como narra?

Com base na leitura do livro de literatura infantojuvenil Os olhos do Marét, de Elizabeth Salgado de Souza, com ilustrações de Gélcio Fortes - respectivamente, Bete Salgado e Gê Fortes, conforme referência do livro (SALGADO, 1997) -, os estudantes foram instigados a refletir sobre a participação da cultura indígena na formação cultural identitária da cidade e de seus moradores. Seguindo a perspectiva do próprio livro, essa atividade deu especial atenção aos detalhes do cotidiano e dos objetos, remetendo mais uma vez às contribuições teórico-metodológicas de Benjamin (1994; 1995). Nela, buscava-se flagrar $\mathrm{o}(\mathrm{s})$ outro(s) no que foi deixado às margens de uma imagem de colônia tecida a partir do ponto de vista e da figura do colonizador, ao mesmo tempo em que se buscava dar valor aos achados, ainda que em pequenos fragmentos, que expressavam a presença indígena na construção dessa história. Assim, favorecia-se a compreensão das relações étnico-raciais e culturas e, sobretudo, os movimentos de resistência que 
permanecem vivos e perceptíveis em costumes e em formas de ver e estar no mundo, muitas vezes consolidadas como traços ou nuances em outras práticas culturais dominantes.

Para encerrar as atividades desse tema, profissionais da ação educativa do MCG promoveram uma oficina de leitura da obra Paisagem Imaginária de Minas, produzida por Guignard em 1947, com a qual os estudantes do LEHIS procederam à última oficina, que incentivava a expressão dos estudantes por meio de desenhos. Para tanto, foi destacado, nessa obra, o entrecruzamento de temporalidades promovido pelo artista, incluindo projeções para o futuro e elementos do passado e do presente de produção, além do fato de Guignard, como quase sempre fazia nas paisagens que desenhava, retratarse. Sua figura não ficava atada aoo pólo da contemplação. Ele se inseria na paisagem entre outros sujeitos. Assim, o entrecruzamento de temporalidades e a visão do sujeito implicado na paisagem foram privilegiadas na condução desse trabalho, que teve início com uma dinâmica de despertar dos sentidos. Essa ideia esteve presente também nas práticas educativas do Museu-Escola do Museu da Inconfidência e em outras atividades coordenadas por Elizabeth Salgado de Souza (CUNHA, 2011), para quem o percurso pela cidade ou por sua história e suas culturas requer o emprego de todos os sentidos, pois é através (ou por meio) deles que se interage com o mundo, criam-se e se reelaboram possibilidades de ser e estar (SOUZA, 1992; 2007).

Tendo em vista que as formas de recepção se modificam historicamente, conforme aponta Benjamin (1994) em "A obra de arte na era da sua reprodutibilidade técnica" e, nesse sentido, compreendendo que, na modernidade capitalista, a visão tem prevalecido sobre os demais sentidos, o projeto RoxoRei atentava para os processos de engendramento histórico das sensibilidades (GALZERANI, 2016) e corroborava práticas que procuram resistir à hierarquização dos sentidos, bem como dos saberes e dos sujeitos. Ao mesmo tempo, o projeto reafirmava uma concepção de estudante ampliada, respeitando-o como um sujeito racional e sensível, pleno de potencialidades (GALZERANI, 2005). 
No processo de produção de conhecimentos, cabe ressaltar, não se ignorava que era necessário fazer um trabalho a contrapelo das tendências prevalecentes, algumas delas expressas em desenhos produzidos pelos estudantes, tais como a idealização ou romantização da figura do índio. Isso endossava para a equipe do projeto a necessidade de um trabalho contínuo e persistente.

Passando para o tema "cidade amor inspiração': preto, branco e nuances", os estudantes foram convidados a visitar a Igreja de Santa Efigênia, atividade guiada pelo guia de turismo Marcelo Hypólito, especializado em roteiros que contemplam a(s) cultura(s) dos negros em Ouro Preto. Por sugestão sua, antes da igreja, foi visitada a mina de ouro Jeje, com o intuito de enfocar o cotidiano de trabalho dos negros escravizados que vieram para Vila Rica. Houve referência a diversas etnias e línguas de povos africanos que vieram para o Brasil e às etnias mais presentes na atividade mineradora. Ao final da visita, o guia chamou atenção para os pigmentos naturais que eram encontrados nas paredes daquela mina e falou sobre a produção de tintas a partir de rochas da região, sobretudo no período colonial.

Em seguida, na visita à Igreja Santa Efigênia, o foco da discussão foi a presença de elementos de cultura africana nas práticas religiosas no Brasil e nos traços dessa cultura na pintura e nos detalhes internos da construção. $\mathrm{O}$ caminho foi aberto para a continuidade das discussões sobre sincretismo religioso, dando margem a aprofundamentos nas atividades com os professores da EEOP e com outros convidados sobre a reinvenção de identidades em espaços coloniais, destacando as relações entre diferentes etnias de negros escravizados (CARVALHO, 2010) e dando enfoque aos aspectos culturais da diáspora africana no Brasil, além dos aspectos econômicos e demográficos (HEYWOOD, 2010). Assim, deslocou-se a imagem do negro para além do prisma da escravidão ou da condição de subjugado na sociedade, o que ganhou reforço com a exposição de reproduções de obras de Guignard sobre famílias negras no Rio de Janeiro, na década de 1930, organizada pelo 
MCG na biblioteca da EEOP. Numa oportunidade de fruição estética, pretendia-se, com tais obras, movimentar imagens do negro na sociedade brasileira e sensibilidades pré-estabelecidas ou engessadas, pois nelas se percebe que o artista preferiu retratar famílias de oficiais, como em A Família do Fuzileiro Naval, de 1935, e/ou momentos de celebração e lazer, como em Os Noivos, de 1937, e em Família na Praça, de 1940. Em função dos objetivos da atividade, não se pretendia ir a fundo numa discussão sobre a recepção da obra do artista no seu contexto histórico-cultural de elaboração, nem problematizar diferentes interpretações críticas a respeito (AULICINO, 2008), mas trazer à tona uma discussão sobre as formas de ver, sobre as perspectivas adotadas na percepção do outro e questionar(-se) sobre o que tem contribuído tanto para a manutenção de imagens engessadas, quanto para a ruptura das formas de ver e de perceber o(s) outro(s).

Continuando as atividades da temática, universitários integrantes do Núcleo de Estudos Afrobrasileiros e Indígenas da UFOP foram convidados para conversar com os estudantes da EEOP sobre as ações realizadas pelo NEAB, sobretudo junto às escolas da região. Depois disso, o diretor da escola conversou sobre a história da capoeira e sua dimensão de resistência cultural. Para finalizar a etapa, a equipe da ação educativa do MCG coordenou a confecção de panôs artísticos pelos estudantes, promovendo a expressão, em linguagem não verbal, do que fora vivenciado e discutido até aquele momento.

A partir da base construída pelo tratamento desses dois temas, o projeto teve continuidade agregando outros temas e pontos da paisagem às discussões, aprofundando o processo de questionamento das memórias que habitam a cidade (em locais de destaque ou às margens da paisagem) e os sujeitos. Era imprescindível associar as discussões sobre memória ao debate sobre as relações étnico-raciais, tanto porque o projeto se desenvolveu em uma cidade símbolo da relação entre memória e a construção da identidade nacional - Ouro Preto se destaca, desde 1933, quando foi considerada Monumento Nacional, como referência na constituição de uma identidade 
e de uma memória nacional-, quanto porque as memórias são palco de lutas e de conflitos étnico-culturais.

Os debates sobre memória, que ganham destaque no país, sobretudo a partir dos anos 1980, estão repletos de críticas aos apagamentos e às exclusões de grupos étnicoculturais e destacam a luta pelo direito à memória como parte da luta pela cidadania, conforme aponta o historiador Ricardo Oriá (1997, p. 129):

[...] emergência dos movimentos sociais populares, protagonizados pela mobilização de trabalhadores, mulheres, negros, índios, homossexuais etc., que, até hoje, reivindicam para si o alcance e o exercício dos direitos de cidadania e a participação política no processo decisório nacional. Esses movimentos colocam na ordem do dia o interesse pelo "resgate" de sua memória, como instrumento de luta e afirmação de sua identidade étnica e cultural.

Portanto, no projeto Roxo-Rei, observar a paisagem foi mais do que um exercício de contemplação, foi o início de um movimento de reinvenção que articulou presente, passado e futuro para promover a compreensão das relações étnicoraciais num cenário amplo de formação de sensibilidades em permanente (re)elaboração. Posicionando-se contra as práticas de dominação, marginalização e apagamento do(s) outro(s), o projeto buscou alargar as imagens do passado para que se pudesse melhor questionar aquelas que, muitas vezes, conforme Benjamin (1995) no texto "Infância em Berlim por volta de 1900”, tornaram-se hábito, de forma que o sujeito nem se lembra como as aprendeu.

\section{Considerações finais}

No projeto Roxo-Rei, aqui abordado, o trabalho foi baseado em uma proposta teórico-metodológica que defende a ação educativa pautada na relação com vivências ou experiências em diferentes espaços e tempos, enfatizando o diálogo entre sujeitos, sujeito e objeto e entre instituições. A paisagem 
urbana foi compreendida, durante seu desenvolvimento, como um cenário sócio-econômico-político-cultural mais amplo do qual todos os moradores fazem parte e que é atravessado por tensões e por conflitos.

Os envolvidos no projeto foram convidados a refletir sobre o vivido em seus espaços cotidianos, sobre as experiências de sujeitos que poderiam ou não ser contemporâneos e sobre outros lugares, espaços e tempos. Eles ingressaram numa dinâmica de trabalho que se desvencilhava, o máximo possível, da transmissão de saberes prontos e acabados que se verificam ao final de uma etapa, para dar lugar a uma construção coletiva fincada em outros ritmos de produção e de percepção, priorizando o caminho percorrido em detrimento do ponto de chegada. Ao mesmo tempo, a interface com a obra de Guignard e a articulação de diferentes saberes fomentou a expressão do vivido em trabalhos artísticos que ampliaram as possibilidades de comunicação e a percepção do vivido, observado e imaginado.

Enfim, no que tange às relações étnico-raciais, o caminho percorrido foi revelando formas de ver e de negar o outro, sem perder de vista a reelaboração contínua dos sentidos e, portanto, trazendo à tona a responsabilidade de cada um nessa reelaboração. Os percursos do Roxo-Rei, sempre atento aos detalhes, revelaram a policromia de uma paisagem onde as cores nem sempre estão em harmonia, e reafirmaram que, como artistas de uma paisagem coletiva em construção, a cada instante todos e cada um se posiciona diante da tela e manuseia uma paleta prenhe de possibilidades de reinventar o que se vê, sente-se, assimila-se. No entanto, sobretudo diante das medidas políticas em curso, que se impõem à educação pública nacional e têm ganhado espaço de debate em diferentes ambientes de produção e de divulgação de conhecimentos, é preciso também aqui reforçar alguns questionamentos que, às vezes, são sublimados nos momentos conclusivos. Nesse sentido, é necessário frisar que, por mais que contribuam com a educação, projetos esporádicos são pontuais, tanto em duração quanto em alcance de público; por 
isso, não é possível negligenciar o grande número de outros estudantes que não puderam ter acesso a um projeto dessa natureza, que demanda investimentos e outros tempos e espaços de elaboração e de construção. Portanto, julgamos urgente o desenvolvimento de projetos que tenham como objetivo refletir sobre as perspectivas de diálogos, reflexões e reelaborações, quer seja sobre memória, relações étnicoraciais, culturas ou quaisquer outros temas relevantes para a formação de uma identidade e para a compreensão do outro e de si mesmo numa educação que se volta cada vez mais para o mercado e para objetivos imediatos.

\section{Referências}

ABREU, Martha; MATTOS, Hebe. Em torno das "Diretrizes curriculares nacionais para a educação das relações étnico-raciais e para o ensino de história e cultura afro-brasileira e africana": uma conversa com historiadores. Estudos Históricos, Rio de Janeiro, v. 21 , n. 41, p. 5-20, jan./ago. 2008.

ANGOTTI-SALGUEIRO, Heliana. Ouro Preto: dos gestos de transformação do "colonial" aos de construção de um "antigo moderno". Anais do Museu Paulista: História e cultura material. São Paulo, v. 4 , n.1 , p. 125-164, 1996.

AULICINO, Marcos Rodrigues. O "Nacionalismo Lírico" de Guignard. In: ENCONTRO NACIONAL DA ASSOCIAÇÃO NACIONAL DE PESQUISADORES EM ARTES PLÁSTICAS PANORAMA DA PESQUISA EM ARTES VISUAIS, 17, 2008, Florianópolis. Anais... Florianópolis: ANPAP; UDESC, 2008. p. 458-467. Disponível em: <http://anpap.org.br/ anais/2008/artigos/043.pdf>. Acesso em: 02 set. 2016.

BENJAMIN. Walter. Magia e Técnica, arte e política: ensaios sobre literatura e história da cultura. Tradução de: Sérgio Paulo Rouanet. 7 ed. São Paulo: Brasiliense, 1994. (Obras Escolhidas, v. 1)

. Rua de Mão Única. Tradução de: Rubens Rodrigues Torres Filho e José Carlos Martins Barbosa. 5. ed. São Paulo: Brasiliense, 1995. (Obras Escolhidas, v. 2)

CARVALHO, Flávia Maria de. Diáspora africana: travessia atlântica e identidades recriadas nos espaços coloniais. Mneme: revista de humanidades, Caicó, v. 11, n. 27, p. 14-24, 2010. 
CUNHA, Nara Rúbia de Carvalho. Primaveras Compartilhadas: (re)significando a docência na relação com cidade, memórias e linguagens. 2016. 252f. Tese (Doutorado em Educação) Faculdade de Educação, Universidade Estadual de Campinas, Campinas, SP, 2016.

- Chão de Pedras, Céu de Estrelas: o Museu-Escola do Museu da Inconfidência, Ouro Preto, década de 1980. 2011. $203 f$. Dissertação (Mestrado em Educação)-Faculdade de Educação, Universidade Estadual de Campinas, Campinas, SP, 2011.

GALZERANI, Maria Carolina Bovério. O Almanaque, a locomotiva da cidade moderna: Campinas, décadas de 1870 e 1880. Campinas, SP: Unicamp; CMU Publicações, 2016.

Imagens entrecruzadas de infância e de produção de conhecimento em Walter Benjamin. In: FARIA, Ana Lúcia Goulart de; DEMARTINI, Zélia de Brito Fabri; PRADO, Patrícia Dias. Por uma cultura de infância: metodologias de pesquisa com crianças. Campinas: Autores Associados, 2005.

HEYWOOD, Linda (Org.). Diáspora negra no Brasil. São Paulo: Contexto, 2010.

OLIVEIRA, Alexandre Augusto de. O Olhar Fotográfico de Luiz Fontana: documentação de Ouro Preto (1930-1960) - Fotografia e arte pública: um estudo de caso. 2006.118p. Dissertação (Mestrado em Artes)-Instituto de Artes, Universidade Estadual de São Paulo, São Paulo, 2006.

ORIÁ, José Ricardo. Memória e ensino de história. In: BITTENCOURT, Circe (Org.) O Saber histórico na sala de aula. São Paulo: Contexto, 1997.

GOVERNO DO ESTADO DE MINAS GERAIS. Petrobras. Projeto Guignard. [s.1.], [2016]. Disponível em: <http://www1. cultura.mg.gov.br/>. Acesso em: 30 set. 2016.

NORA, Pierre. Entre memória e história: a problemática dos lugares. Projeto História, [São Paulo], v. 10, p. 7-28, dez. 1993.

SALGADO, Bete. Os olhos do Marét. Ilustração de: Gê Fortes. Belo Horizonte: MinC;IPHAN; Museu da Inconfidência, 1997.

SOUZA, Elizabeth Salgado de. Museus: testemunhas do tempo. Amae Educando, Belo Horizonte, ano 25, n. 228, p. 4-7, jun. 1992. Saberes e Fazeres do Patrimônio Imaterial de Ouro Preto.

Revista da Academia Mineira de Letras, Belo Horizonte, ano 84, v. 43, p. 99-105, jan./mar. 2007. 
THOMPSON, Edward Palmer. Costumes em comum: estudos sobre a cultura popular tradicional. São Paulo: Companhia das Letras, 1998.

Submetido em: 18/11/2016

Aprovado em: 14/12/2016

\title{
FROM THE MANY COLORS OF A CITY: THE ROXO-REI PROJECT AND BLACK AND INDIAN MEMORIES INTHE OURO PRETO LANDSCAPE
}

\begin{abstract}
This article presents part of a project developed between Guignard House Museum and a school of Basic Education of Minas Gerais, which focused on the landscape of the city of OuroPreto in a production history and educational knowledge in dialogue with art in 2014. In particular, we cut up the first part of this project, which was promoted reflection on the presence of Indians and blacks in the formation of this landscape, fostering a discussion that wove different times and promoting a comparison between present and past.
\end{abstract}

Keywords: Production of knowledge. Memory. Ethnic and racial relations. Alberto da VeigaGuignard. 